\title{
Extratos Vegetais com Propriedades Nematicidas e Purificação do Princípio Ativo do Extrato de Leucaena leucocephala*
}

\author{
Flávia R. Cunha ${ }^{1 * *}$, Denilson F. Oliveira ${ }^{1}$ \& Vicente P. Campos ${ }^{2}$ \\ 1Departamento de Química, e-mail: denilson@ufla.br; ${ }^{2}$ Departamento de Fitopatologia, Universidade Federal de Lavras, \\ Cx. Postal 37, CEP 37200-000, Lavras, MG
}

(Aceito para publicação em 18/02/2003)

Autor para correspondência: Denilson F. Oliveira

CUNHA, F.R., OLIVEIRA, D.F. \& CAMPOS, V.P. Extratos vegetais com propriedades nematicidas e purificação do princípio ativo do extrato de Leucaena leucocephala. Fitopatologia Brasileira 28:438-441. 2003.

\section{RESUMO}

Inicialmente buscou-se identificar plantas com extratos metanólicos ativos in vitro contra o nematóide Panagrellus redivivus. Das 24 espécies vegetais estudadas, constatou-se que os melhores resultados foram obtidos com Leucaena leucocephala, que causou mortalidade de 93\% dos indivíduos expostos ao seu extrato por $24 \mathrm{~h}$. Em seguida, submeteu-se o referido extrato a fracionamento direcionado pelos testes in vitro com $P$. redivivus, o que possibilitou isolar uma substância nematicida que, segundo análises preliminares, correspondia a um alcalóide.

Palavras-chave adicionais: nematóide, Panagrellus redivivus, planta.

\begin{abstract}
Nematocidal plant extracts and purification of active ingredients of Leucaena leucocephala extract

Initially this work was aimed to identify plant methanolic extracts toxic in vitro to the nematode Panagrellus redivivus. Among 24 plant species studied, Leucaena leucocephala afforded the best

results, as $93 \%$ of the nematodes were dead after exposure to its extract during $24 \mathrm{~h}$. Thus, such extract was submitted to a purification process guided by in vitro assays with $P$. redivivus. As a result, one substance active against such nematode was isolated. According to preliminary analysis, that seems to be an alkaloid.
\end{abstract}

Os nematóides parasitas de plantas causam consideráveis reduções na produtividade agrícola, já que acarretam perda da ordem de US\$ 100 bilhões anualmente (Tihohod, 1993). Dentre as táticas de controle desses fitoparasitas, destaca-se o uso de nematicidas sistêmicos que, além de aumentarem os custos de produção, apresentam riscos ao homem e ao meio ambiente (Campos et al., 1998). Uma alternativa de menor impacto ecológico tem sido o uso de plantas antagônicas, que produzem metabólitos com propriedades nematostáticas ou nematicidas, após a penetração do fitonematóide, ou podem tê-los constitutivamente. Algumas dessas substâncias são excretadas pelas raízes, como no caso do $\alpha$-tertienila, produzido por Tagetes erecta Linn. Outros exemplos de substâncias de origem vegetal com propriedades nematicidas são o alcalóide monocrotalina, o ácido butírico e o pirocatecol, isolados de tecidos de Crotalaria spectabilis Roth e Eragrostis curvula Nees, respectivamente (Ferraz \& Vale, 1997).

Com vistas a contribuir para o desenvolvimento de novos métodos de controle de fitonematóides, inicialmente, buscou-se identificar extratos vegetais com atividade antagônica in vitro ao nematóide bacteriófago Panagrellus redivivus $\mathrm{L}$. Apesar de não se tratar de um parasita de plantas,

\footnotetext{
*Parte da Dissertação de Mestrado do primeiro autor. Universidade Federal de Lavras (2002).

***Bolsista do CNPq.
}

a referida espécie foi utilizada pelo fato de poder ser facilmente mantida e multiplicada em laboratório, o que representa vantagem sobre as espécies fitoparasitas, que demandam o cultivo de plantas infetadas. Além de buscar identificar extratos vegetais com propriedades nematicidas, este trabalho também é parte de um projeto que visa ao estabelecimento de métodos mais fáceis de detecção de substâncias nematicidas, para serem empregados em períodos cujas condições sejam adversas à manutenção e multiplicação de fitonematóides.

Por ter proporcionado a maior taxa de mortalidade de $P$. redivivus, o extrato de Leucaena leucocephala (Lam) De Wit foi submetido a fracionamento, visando à purificação e identificação da substância nematicida.

\section{Obtenção dos extratos vegetais}

Para o presente trabalho foram colhidas folhas de todas as plantas estudadas e flores de Pelargonium hortorum L. H. Bailey e de Dredanthema grandiflorum Kitam, no campus da Universidade Federal de Lavras (Tabela 1). Um grama de cada amostra foi picado e imerso em metanol P.A. por $48 \mathrm{~h}$. Filtraramse as suspensões resultantes em algodão e colocaram-se os resíduos obtidos em mais metanol. Após 48 h, procedeu-se a nova filtragem em algodão. As fases metanólicas obtidas nas duas filtrações foram reunidas e, em seguida, concentradas em evaporador rotatório até secura. O resíduo obtido foi solubilizado em $10 \mathrm{ml}$ de solução aquosa de Tween 80 [monooleato 
Extratos vegetais com propriedades nematicidas e purificação do princípio...

de polioxietileno (20) sorbitan] a $1 \%(\mathrm{~g} / \mathrm{ml})$, para ser usado no teste in vitro com $P$. redivivus.

\section{Teste in vitro com $P$. redivivus}

Placas de Petri contendo meio de cultura aveia-água, infestadas com $P$. redivivus, foram lavadas com água destilada e esterilizada, originando uma suspensão de nematóides que foi imediatamente passada através de peneiras sobrepostas de 60, 200 e 400 mesh. Em funil de vidro fechado na parte inferior (Funil de Baermann), contendo água e peneira de malha fina com filtro de papel, foram vertidos os nematóides retidos na peneira de 400 mesh, usando-se jatos de água provenientes de uma pisseta. Após 30 min, a parte inferior do funil foi aberta, o que permitiu recolher uma suspensão aquosa de nematóides, que foi calibrada com a adição ou retirada de água, para 20-30 nematóides por $10 \mu \mathrm{l}$.

Em células de placas tipo Elisa, previamente lavadas com detergente, álcool e água destilada, foram colocados $10 \mu \mathrm{l}$ da suspensão de nematóides e $240 \mu \mathrm{l}$ da amostra a ser testada. As contagens do número de indivíduos vivos e mortos foram realizadas com 24,36 e 48 h, com auxílio de microscópio de objetiva invertida. Empregou-se como testemunha positiva solução aquosa de Aldicarbe (200 ppm) e como testemunha negativa solução aquosa de Tween 80 a $1 \%$ (g/ml). Empregaramse seis repetições em todos os casos, cujos resultados obtidos foram transformados para percentagem e submetidos à análise de variância. As médias foram comparadas pela aplicação do teste de Tukey (5\%). Consideraram-se indivíduos mortos aqueles sem movimento.

\section{Fracionamento do extrato de L. leucocephala}

O extrato metanólico de $520 \mathrm{~g}$ de folhas frescas de $L$. leucocephala, obtido conforme descrito anteriormente, foi concentrado em evaporador rotatório até 1/5 do volume inicial, o que resultou em suspensão aquosa. Esta foi, a seguir, submetida à extração com hexano $(2 \times 55 \mathrm{ml})$ e acetato de etila ( 2 x $55 \mathrm{ml}$ ). Obtiveram-se assim, três fases líquidas, das quais se retiraram alíquotas correspondentes a $0,1 \%$ dos respectivos volumes, que foram concentradas em evaporador rotatório até secura e solubilizadas em $5 \mathrm{ml}$ de Tween 80 a $1 \%(\mathrm{~g} / \mathrm{ml})$, para serem submetidas ao teste in vitro com $P$. redivivus.

Os $200 \mathrm{ml}$ da fase aquosa, resultantes do processo de extração com hexano e acetato de etila, foram liofilizados, rendendo resíduo com massa igual a 18,34 g. Realizaram-se sucessivas lavagens de $0,035 \mathrm{~g}$ de tal resíduo com acetato de etila $(4 \mathrm{ml})$, metanol $(4 \mathrm{ml})$ e água $(4 \mathrm{ml})$. As três fases líquidas resultantes das lavagens foram concentradas em evaporador rotatório até secura e dissolvidas em $5 \mathrm{ml}$ de solução aquosa de Tween 80 a $1 \%(\mathrm{~g} / \mathrm{ml})$, para serem submetidas ao teste in vitro com $P$. redivivus.

O restante do resíduo obtido pelo processo de liofilização foi lavado várias vezes com metanol (7 x $100 \mathrm{ml})$. Todas as fases metanólicas foram reunidas e concentradas sob vácuo até secura, o que originou resíduo com massa de $12,82 \mathrm{~g}$. Parte deste $(3,08 \mathrm{~g})$ foi fracionada em coluna de $3 \times 17$ cm de sílica gel 60 (Merck), empregando-se acetato de etila
(150 ml), metanol (150 ml), água (150 ml) e HCl 0,1 M (150 ml), como eluentes. Alíquotas das quatro frações obtidas, correspondentes a $0,8 \%$ do volume de cada, foram concentradas em evaporador rotatório até secura e dissolvidas em $5 \mathrm{ml}$ de solução aquosa de Tween 80 para serem submetidas ao teste in vitro com $P$. redivivus.

A fração de $\mathrm{HCl}$ 0,1 M foi concentrada sob vácuo até secura, o que originou resíduo semi-sólido, com massa de 0,179 g. Este, mais uma vez, foi fracionado por cromatografia em coluna de 3 x $15 \mathrm{~cm}$ da mesma sílica. Para tanto, empregaram-se $150 \mathrm{ml}$ de cada uma das soluções: acetato de etila/ ácido acético (10:3); acetato de etila/ metanol/ácido acético (8,5:1,5:3); acetato de etila/ metanol/ácido acético (8:2:3)/ acetato de etila/metanol/ ácido acético (6,7:3,3:3) e acetato de etila/metanol/ácido acético (5:5:3), como eluentes. Obtiveram-se 60 frações, que foram combinadas de acordo com resultados de análise por cromatografia em camada fina $(\mathrm{CCF})$ e por espectrometria no infravermelho. Com isso, ao final havia dez frações combinadas: 1-12, 13-19, 20-22, 23-27, 28-29, 30-35, 36-52, 53-54, 55-57 e 5860. Alíquotas correspondentes a 5\% do volume de cada foram concentradas em evaporador rotatório até secura e dissolvidas em $5 \mathrm{ml}$ de solução aquosa de Tween 80 a $1 \%(\mathrm{~g} / \mathrm{ml})$, para serem submetidas ao teste in vitro com $P$. redivivus. Após concentração, a fração combinada 58-60 foi analisada por CCF, com placas de sílica gel. Para a revelação, empregaram-se solução etanólica de ácido fosfomolíbdico e reagente de Dragendorf (Wagner et al., 1983). Em ambos os casos, observou-se que tal fração era composta por apenas uma substância que tinha Rf (distância percorrida pela substância/ distância percorrida pelo eluente) igual a 0,25 quando se empregava acetato de etila/metanol /ácido acético (5:5:3) como eluente. Após total remoção dos solventes da fração 58-60 sob vácuo, obteve-se um sólido com massa de 0,02 g.

Das 24 espécies vegetais testadas (Tabela 1), obtiveramse resultados mais promissores com os extratos de $L$. leucocephala e Paspalum notatum Flüggé, que induziram $98,69 \%$ e $94,43 \%$ de mortalidade de $P$. redivivus, respectivamente (Tabela 2). No caso específico de L. leucocephala, os dados apresentados corroboram os resultados de Gonzaga (1992) que, em testes in vivo, conseguiu redução do número de galhas de Meloidogyne incognita (Kofoid \& White) Chitwood em plantas indicadoras cultivadas após L. leucocephala. Ademais, está de acordo com resultados de testes in vitro realizados com juvenis do segundo estádio (J2) de M. incognita e de Meloidogyne exigua Goeldi. Em ambos os casos, o extrato de L. leucocephala provocou altas taxas de mortalidade de J2 (Costa, 1999; 2000). Em relação a P. notatum, Rodríguez-Kábana \& Canullo (1992) comprovaram bons resultados desta gramínea no controle de Meloidogyne arenaria Neal e Heterodera glycines Ichnohe, e a caracterizaram como não hospedeira desses nematóides. $\mathrm{O}$ fato de o extrato ter apresentado atividade contra $P$. redivivus foi um indício de que uma das suas formas de ação contra fitonematóides pode basear-se na produção de substâncias nematicidas.

Para várias das outras plantas testadas, esperava-se a obtenção de resultados confirmando a atividade nematicida, 
uma vez que havia relatos na literatura demonstrando que podiam produzir substâncias ativas contra fitonematóides (Ferraz \& Valle, 1997). Tagetes erecta Linn, por exemplo, da qual já foram isoladas substâncias tóxicas a nematóides, forneceu resultado estatisticamente idêntico ao da testemunha água. De forma análoga, pode-se mencionar Zinnia elegans Jacq, cujo extrato tem considerável ação contra $M$. incognita (Bano et al., 1986). Ainda é possível citar Crotalaria juncea L. (Silva et al., 1990), Ricinu s communis L. (Rodríguez-Kábana \& Canullo, 1992), Stylosanthes gracilis H. B. K. (Gonzaga, 1992) e Catharanthus roseus G. Don (Krishnamurthy \& Murthy, 1993), que apesar de se mostrarem ativas contra fitonematóides, não tiveram nenhum efeito sobre $P$. redivivus.

Nos casos de Bougainvillea glabra Choisy e Carica papaia L., apesar dos baixos valores obtidos, os extratos correspondentes apresentaram efeitos contra $P$. redivivus, o que está de acordo com dados da literatura que relatam tais plantas como antagônicas a fitonematóides (Rao \& Reddy, 1992; Siddiqui et al., 1992).

Quanto aos extratos de Allium sativum L. e de Allium cepa L., que são ativos contra fitonematóides (Costa, 2000), observou-se que a percentagem de $P$. redivivus mortos após 24 h estava próxima daquela obtida para o extrato de $P$. notatum.

Os dados obtidos indicam que não há uma relação simples entre o comportamento de $P$. redivivus e de fitonematóides frente a substâncias de origem vegetal. Apenas para

TABELA 1 - Espécies vegetais coletadas para a obtenção dos extratos vegetais empregados nos testes in vitro com Panagrellus redivivus

\begin{tabular}{|c|c|c|}
\hline Nome cientifico & Familia & Nome comum \\
\hline Allium cepa $\mathrm{L}$. & Poaceae & cebola \\
\hline A.sativum L. & Poaceae & alho \\
\hline Aspargus densiflorus Myersii & Liliaceae & aspargo ornamental \\
\hline Bougainvillea glaba Choisy & Nyctaginaceae & buganvile \\
\hline Brachiaria decumbens Stapf & Poaceae & capim-Braquiária \\
\hline Carica papaya $\mathrm{L}$. & Caricaceae & Mamão \\
\hline Catharanthus roseus G. Don & Apocynaceae & vinca \\
\hline Clerodendrum thomsonae Balf & Verbenaceae & clerodendro trepador \\
\hline Coffea arabica $\mathrm{L}$. & Rubiaceae & Café \\
\hline Crotalaria juncea L. & Leguminosae & Crotalária \\
\hline Dredanthema grandiflorum Kitam & Compositae & Crisântemo \\
\hline Eucaliptos sp & Myrtaceae & eucalipto \\
\hline Euphorbia pulcherrima Willd & Euphorbiaceae & bico-de-papagaio \\
\hline Ficus carica $\mathrm{L}$. & Moraceae & figo \\
\hline Leucaena leucocephala (Lam) De Wit & Leguminosae & leucena \\
\hline Leucaena $\mathrm{sp}$ & Leguminosae & Árvorede leucena \\
\hline Mangifera indica $\mathrm{L}$. & Anacardeaceae & manga \\
\hline Paspalum notatum FIÜggé & Poaceae & grama-batatais \\
\hline Pelargonium hortorum L. H. Bailey & Geraniaceae & Gerânio \\
\hline Plumeria rubra Linn & Apocynaceae & jasmim-manga \\
\hline Ricinus communis L. & Euphorbiaceae & mamona \\
\hline Stylosanthes gracilis H. B. K. & Leguminosae & stilosantes \\
\hline Tagetes erecta Linn & Compositae & cravo-de-defunto \\
\hline Zinnia elegans Jacq & Compositae & Zínia \\
\hline
\end{tabular}

Coletaram-se folhas de todas as plantas e flores de $P$. hortorum e $D$. grandiflorum alguns dos extratos empregados, como os de A. cepa, A. sativum, B. glabra, C. papaia L. leucocephala e $P$. notatum, parece possível empregar o nematóide de vida livre para testes iniciais. No entanto, como esse resultado é decorrente de comparações com dados da literatura, obtidos em condições que não seguem a metodologia aqui descrita, faz-se necessário estudar o problema de forma mais minuciosa. De qualquer forma, como o maior percentual de mortalidade de $P$. redivivus nos testes in vitro foi observado para o extrato de $L$. leucocephala que, como mencionado anteriormente, tem atividade contra fitonematóides, selecionou-se a referida planta para a etapa de purificação de substâncias nematicidas. Sendo assim, submeteu-se o respectivo extrato metanólico concentrado à partição líquido-líquido, o que permitiu obter três conjuntos de substâncias distintas: apolares (fase de hexano), semipolares (fase de acetato de etila) e polares (fase aquosa) (Harborne, 1998). Verificou-se que apenas a fase aquosa apresentava atividade contra $P$. redivivus, o que deixou evidente que a substância nematicida produzida por tal planta era consideravelmente polar.

TABELA 2 - Mortalidade de Panagrellus redivivus por extratos de diferentes plantas e por Aldicarbe a 200 ppm

\begin{tabular}{lcc}
\hline \hline & Panagrellus redivivus mortos (\%) \\
\cline { 2 - 3 } Tratamento & $\mathbf{2 4} \mathbf{~ h}$ & $\mathbf{4 8} \mathbf{~ h}$ \\
\hline Carica papaia & $0,00 \mathrm{a}$ & $15,36 \mathrm{~b}, \mathrm{c}$ \\
Pelargonium hortorum & $0,00 \mathrm{a}$ & $0,00 \mathrm{a}$ \\
P. hortorum (flores) & $0,00 \mathrm{a}$ & $0,41 \mathrm{a}$ \\
Aspargus densiflorus & $0,33 \mathrm{a}$ & $0,90 \mathrm{a}$ \\
Euphorbia pulcherrima & $0,36 \mathrm{a}$ & $0,36 \mathrm{a}$ \\
Ficus carica & $0,39 \mathrm{a}$ & $0,91 \mathrm{a}$ \\
Eucaliptos sp & $0,46 \mathrm{a}$ & $0,39 \mathrm{a}$ \\
Brachiaria decumbens & $0,62 \mathrm{a}$ & $11,054 \mathrm{~b}$ \\
Dredanthena grandiflorum (flores) & $0,87 \mathrm{a}$ & $5,05 \mathrm{a}$ \\
Zinia elegans & $1,29 \mathrm{a}$ & $5,98 \mathrm{a}, \mathrm{b}$ \\
Stylosanthes gracilis & $2,22 \mathrm{a}$ & $1,90 \mathrm{a}$ \\
Tagetes erecta & $2,45 \mathrm{a}$ & $1,19 \mathrm{a}$ \\
Plumeria rubra & $3,07 \mathrm{a}$ & $3,07 \mathrm{a}$ \\
Catharanthus roseus & $3,18 \mathrm{a}$ & $5,40 \mathrm{a}, \mathrm{b}$ \\
Clerodendrum thomsonae & $3,55 \mathrm{a}$ & $4,78 \mathrm{a}$ \\
Crotalaria juncea & $3,59 \mathrm{a}$ & $4,41 \mathrm{a}$ \\
Ricinus communis & $3,85 \mathrm{a}$ & \\
Leucaena sp & $3,96 \mathrm{a}$ & $29,75 \mathrm{c}$ \\
Mangifera indica & $4,96 \mathrm{a}$ & $26,43 \mathrm{c}$ \\
Dredanthema grandiflorum & $5,29 \mathrm{a}$ & $36,33 \mathrm{c}$ \\
Coffea arabica & $5,40 \mathrm{a}, \mathrm{b}$ & \\
Bougainvillea glabra & $10,02 \mathrm{~b}$ & $23,39 \mathrm{c}$ \\
Allium sativum & $18,00 \mathrm{~b}, \mathrm{c}$ & \\
A. cepa & $27,83 \mathrm{c}$ & \\
Paspalum notatum & $31,97 \mathrm{c}$ & $94,43 \mathrm{~d}$ \\
Leucaena leucocephala & $93,26 \mathrm{~d}$ & $98,69 \mathrm{~d}$ \\
Aldicarbe & $0,57 \mathrm{a}$ & $\mathrm{d}$ \\
\hline
\end{tabular}

*Médias seguidas pela mesma letra na coluna não diferem significativamente entre si pelo teste de Tukey a $5 \%$ de probabilidade. Coeficiente de variação igual a $5,63 \%$ e $12,23 \%$ para leituras com 24 h e 48 h, respectivamente 
Extratos vegetais com propriedades nematicidas e purificação do princípio...

Como a fase aquosa era a única apresentando atividade contra $P$. redivivus, foi liofilizada e submetida ao próximo processo de fracionamento. Inicialmente, uma pequena alíquota do resíduo obtido foi subseqüentemente lavada com acetato de etila, metanol e água, o que gerou três fases líquidas. A mais ativa era a fase metanólica, com mortalidade semelhante $(\mathrm{P} \leq$ $0,01)$ ao Aldicarbe. Tal resultado indicava que a solubilidade da substância ativa em acetato de etila era muito baixa e alta em metanol. Somando-se isto ao fato da massa da fase de acetato de etila, após remoção do solvente sob vácuo, ser visualmente desprezível perante a massa da fase de metanol, optou-se por lavar o resíduo da liofilização várias vezes com metanol. Acreditava-se que com isso, toda a substância ativa seria dissolvida em metanol.

Após concentração da solução metanólica, submeteuse parte do resíduo obtido ao fracionamento em coluna de sílica gel, o que resultou em quatro frações. Destas, apenas a de $\mathrm{HCl}$ 0,1 M se mostrou ativa contra $P$. redivivus, o que também é indicativo de alta polaridade por parte da substância nematicida.

A fração de $\mathrm{HCl}$ 0,1 M foi concentrada sob vácuo e submetida a outro processo cromatográfico, o que resultou na obtenção de 60 frações. Ao serem combinados, os números de frações foi reduzido para dez, das quais apenas as cinco últimas a eluírem da coluna se mostraram ativas contra $P$. redivivus (Tabela 3)

As cinco frações ativas do último processo cromatográfico foram submetidas à análise por cromatografia em camada fina, mas só foi possível notar alguma mancha no caso da fração 58-60. Para esta, observou-se que havia apenas uma substância quando se utilizava o reagente de Dragendorf como revelador. Este resultado indicava que a substância presente na fração 58-60 continha pelo menos um átomo de nitrogênio na sua estrutura (Wagner et al., 1983), o que está de acordo

TABELA 3 - Mortalidade de Panagrellus redivivus após incubação por $36 \mathrm{~h}$ em frações resultantes da cromatografia em coluna da fração de $\mathrm{HCl}$ do extrato de Leucaena leucocephala.

\begin{tabular}{|c|c|}
\hline Fração & Panagrellus redivivus mortos (\%)* \\
\hline 1 a 12 & $1,95 \quad \mathrm{~d}$ \\
\hline 13 a 19 & $2,19 \quad \mathrm{~d}$ \\
\hline 20 a 22 & 7,11 \\
\hline 23 a 27 & 5,96 \\
\hline 28 a 29 & 6,91 \\
\hline 30 a 35 & $78,08 \mathrm{bc}$ \\
\hline 36 a 52 & $71,49 \quad \mathrm{c}$ \\
\hline 53 e 54 & $79,07 \mathrm{bc}$ \\
\hline 55 a 57 & $87,56 \mathrm{ab}$ \\
\hline 58 a 60 & 93,37 a \\
\hline Testemunha água & 6,27 \\
\hline Aldicarb & $100,00 \mathrm{a}$ \\
\hline
\end{tabular}

*Médias seguidas pela mesma letra na coluna não diferem significativamente entre si pelo teste de Tukey a $5 \%$ de probabilidade. Coeficiente de variação igual a $18,45 \%$. com dados da literatura que sugerem que a substância nematicida produzida por L. leucocephala seja um alcalóide (Villaseñor et al., 1997).

\section{REFERÊNCIAS BIBLIOGRÁFICAS}

BANO, M., ANVER, S. \& TIVAGI, S.A. Evaluation of nematicidal properties of some members of the family Compositae. International Nematology Network Wersletter 3:15-25. 1986.

CAMPOS, V.P., SOUZA, J.T. \& SOUZA, R.M. Controle de fitonematóides por meio de bactérias. Revisão Anual de Patologia de Plantas 285-327. 1998.

COSTA, M.J.N. Filtrados de culturas fúngicas e extratos de plantas e de estercos animais, com ação antagonista a Meloidogyne incognita (Kofoid \& White) Chitwood. (Tese de Mestrado). Lavras. Universidade Federal de Lavras. 2000.

COSTA, M.J.N., AMARAL, D.R., CAMPOS, V.P. \& OLIVEIRA, D.F. Efeito de extratos vegetais na mobilidade de juvenis do segundo estádio de Meloidogyne spp. Anais, XIII Encontro Regional da Sociedade Brasileira de Química-MG, São João del Rei, MG. 1999. p. 151 .

FERRAZ, S. \& VALLE, L.A. Controle de fitonematóide por plantas antagônicas. Viçosa. UFV. 1997. Cadernos Didáticos.

GONZAGA, V. Reação de cultivares a linhagens de feijão (Phaseolus vulgariws L.) a Meloidogyne javanica e Meloidogyne incognita raça 3 e avaliações de plantas antagonistas para o controle destes nematóides. (Tese de Mestrado). Viçosa. Universidade Federal de Viçosa. 1992.

HARBORNE, J.B. Phytochemical Methods. A Guide to Modern Techniques of Plant Analysis. $3^{\text {rd }}$ ed. London. Chapman \& Hall. 1998.

KRISHNAMURTHY, G.V.G. \& MURTHY, P.S.N. Further studies with plant extracts on root-knot nematode (Meloidogyne javanica) larvae. In: Chari, M.S. \& Ramaprasad, G. (Eds.) Botanical Pesticides in Integrated Pest Management. Rajahmundry. Indian Society of Tobacco Science. 1993. pp.438-448.

RAO, M.S. \& REDDY, P. Studies on the comparative efficacy of certain plant leaves and carbofuran in the management of Meloidogyne incognita on tomato. Current Nematology 3:5-6. 1992.

RODRIGUEZ-KABANA，R. \& CANULLO G.H. Cropping systems for the management of phytonematodes. Phytoparasitica 20:211-224. 1992.

SIDDIQUI, Z.A., HASEEB, A. \& ALAM, M.M. Control of plant parasitic nematodes by soil amendments with latex bearing plants. Indian Journal of Nematology 22:25-28. 1992.

SILVA, G.S., FERRAZ, S. \&ANTOS, J.M. Efeito de Crotalaria spp. sobre Meloidogyne javanica, $M$. incognita raça 3 e M. exigua. Fitopatologia Brasileira 15:94-96. 1990.

TIHOHOD, D. Nematologia Agrícola Aplicada. 1. Jaboticabal. Funep. 1993.

VILLASEÑOR, I.M., GAJO, R.M.T. \& GONDA, R.C. Bioactivity studies on the alkaloid extracts from the seed of Leucaena leucocephala. Phytotherapy Research 11:615-617. 1997.

WAGNER, H., BADT, S. \& ZGAINSKI, E.M. Plant Drug Analysis - A Thin Layer Chromatography Atlas. Berlin. 1983. 